\title{
Effect of nesting on sleep pattern among preterm infants admitted in NICU.
}

\author{
Mony $\mathbf{K}^{1^{*}}$, Vindra Selvam ${ }^{2}$, Krishnakumar Diwakar ${ }^{3}$, Vijaya Raghavan $\mathbf{R}^{4}$ \\ ${ }^{1}$ Departement of Pediatric Nursing, MOSC College of Nursing, Malankara Orthodox Syrian Church Medical College, \\ Kolenchery, Ernakulam District, Kerala \\ ${ }^{2}$ Department of Obstetrics and Gynecology Nursing, Ashwini College of Nursing, Thrissur, Kerala \\ ${ }^{3}$ Department of Neonatology, Malanakara Orthodox Syrian Church Medical College, Kolenchery, Ernakulam District, \\ Kerala \\ ${ }^{4}$ Department of Research, Saveetha Institute of Medical and Dental Sciences (SIMATS), Chennai, Tamil Nadu, India
}

\begin{abstract}
Preterm infants are babies born before completion of $37 \mathrm{w}$ of gestation. Their organs are immature especially brain. Sleep has a vital role in brain development and maturation in infants. Neonatal intensive care unit is a place where infant's comfort is disturbed by many environmental stimuli. So the sleep is disrupted. Nesting facilitates transformation of sleep pattern from erratic disturbed spells to deep peaceful nights and contented days. This study aimed to investigate the effect of nesting on sleep pattern of infants hospitalized in NICUs. This crossover clinical trial was performed at a tertiary Neonatal Intensive Care Unit (NICU). 21 preterm infants who met the inclusion criteria were enrolled. They were randomly assigned to two groups of nest and routine procedure. Sleep status was evaluated by using neonatal sleep assessment Scale. Duration of Total Sleep Time per cycle (TST) and duration of each stage such as quiet sleep, active sleep indeterminate sleep were recorded and analysed by using paired t-test. Duration of Total Sleep Time per cycle (TST) and duration of each stage were significantly higher among preterm with nesting than usual procedure of care $(\mathbf{p}<0.001)$. Duration of sleep time in each stages shows, duration of active sleep is significantly reduced (34.76) with nesting as compared to routine care (39.55) although which is not significant $(t=1.134, P=0.270)$ there is significant increase in quiet sleep $(63.62 \pm 17.957)$ with nesting than with routine care and indeterminate sleep time was increased with nesting as compared with sleep in routine care which is highly significant $(t=4.570$, $p<0.001),(t=2.297, p=0.003)$ at 0.05 level of significance. The present study results supports the use of nesting aids in increase sleep and duration of quiet sleep and aids in stability of physiological parameters. Thus using nesting for preterm infant is recommended to facilitate infant's quality of sleep in NICU.
\end{abstract}

Keywords: Sleep, Preterm infants, Nesting.

Accepted on February 12, 2018

\section{Introduction}

Preterm infants born early with immature neurological functioning may live in the Neonatal Intensive Care Unit (NICU) for an extended period of time. From birth on, these infants face a series of challenges in various areas of development. One of the major challenges in the first months of life is state organization, the development of integrated and coordinated patterns of sleep-wake states. Stable sleep-wake organization reflects the maturation of the central nervous system [1]. There are globally 5\% to $18 \%$ and in India- $21 \%$ of babies, almost 3.6 million premature births and in Kerala-36.7\% 1 million children die each year due to complications. Over 2 million children today have some type of sleep disorder [2]. In neonates, the sleep cycle is not well developed, includes three stages of active, quiet and indeterminate sleep. Active sleep is characterized by the presence of closed eyes, rapid or slow eye movements under closed eye lids irregular breathing which is more rapid and shallow, variability in heart rate, twitching arms and legs ,may appear to smile and there may be periodic groaning or crying. Quiet sleep is marked by deep regular breathing and lying still with the occasional myoclonic jerk or startle and Indeterminate sleep is the stage between active sleep and quiet sleep where sleep characteristics are not clearly definable. Preterm infants showed developmental changes in state organization with increased quiet sleep, drowsy, and awake, decreased active sleep, and more defined and less diffuse states over age [3]. A significant gender effect was found, with males having less active sleep, drowsier, more awake, less defined, and more 
diffuse states compared with females [3]. Sleep-wake transitions in premature neonates predict early development reveals infants whose sleep-state transitions were mainly characterized by shifts between quiet sleep and wakefulness exhibited the best development, including greater neonatal neuromaturation, less negative emotionality, better cognitive development, and better verbal, symbolic and executive competences at 5 years. Infants who cycled were mainly between states of high arousal, such as active sleep and cry or between short episodes of active and quiet sleep showed poorer outcomes [4]. Nesting is one of the method helps to maintain position which minimizes the effect of environmental stimuli of NICU and there by promote comfort and sleep. Nesting facilitates transformation of sleep pattern from erratic disturbed spells to deep peaceful nights and contented days thus, conserving energy and minimizing weight loss [5]. The present study was aimed to observe the effect of Nesting on sleep pattern among preterm infants admitted in NICUs.

\section{Materials and Methods}

This is a randomized controlled clinical trial to assess the effect of nesting on sleep pattern among preterm infants, conducted in cross over design to control confounding factors of sleep of preterm infants. The study was conducted from March 2017 to May 2017 in NICU of MOSC Medical College, Kerala. The selection of setting was purposive in nature. A total of 21Preterm infants satisfying the inclusion and exclusion criteria were included in the study after obtaining the written informed consent from the parents. The study was approved by institutional human ethical committee. Institutional Ethical committee of Saveetha University and MOSC Medical College approved this research (Approval No 022/08/2016/IEC/SU and MOSC/IEC/239/2017. The following criterion was used in selecting the participants.

\section{Inclusion criteria}

1. Pre-term infants with weight between 1200-2000 g.

2. With post conceptual age between 30 and $36 \mathrm{w}$.

3. Admitted in NICU with spontaneous breathing with no need of assisting device.

4. No major congenital defects or abnormal neurological findings including intraventricular hemorrhage.

5. No consumption of illicit narcotics or additive substances by the mothers during pregnancy.

6. Not treated with sedatives $24 \mathrm{~h}$ prior to intervention.

After selecting the participants, the participants were randomly allocated for nesting and routine procedure of wrapping. Socio demographic data was recorded from medical records department of hospital. Feeding Interval of ICU was $2 \mathrm{~h}$. After one intervention next two hours infant was kept on wash out period for $2 \mathrm{~h}$ to prevent carry over effect of first intervention and then same subject was kept on second intervention. These infants were allowed to sleep after feed, duration of sleep was observed during sleep waking period between inter epoch of two feeds by using sleep assessment scale.

\section{Methods}

Demographic data was collected by using a structured questionnaire. It consists of age, sex, gestational age and birth weight. Sleeping pattern was assessed by using sleep assessment scale of preterm neonate. Content validity and reliability of the tool were obtained by giving to experts in the field of neonatology and nursing.

\section{Data analysis}

Data were analysed by using SPSS 20.0 version. Data was presented as mean $\pm \mathrm{SD}$. P value less than 0.05 was considered significant.

\section{Results}

Out of 21 infants in the study 12 were male and 9 were female. Mean of gestational age of study subjects were $32.81 \pm 1.365$ w. The mean of post natal age of study subjects were $6.38 \pm$ $5.343 \mathrm{~d}$. Mean birth weight of the subjects were $1.67 \pm 0.1849$ (Table 1). Total duration of sleep time showed that mean value of total duration of sleep is significantly higher (113 min) among infant with nesting as compared to routine care (86 min) which is highly significant $(\mathrm{t}=4.930, \mathrm{P}<0.001)$ (Table 2$)$. Paired t-test showed that difference in total duration of sleep time with nesting as compared to routine care was significant (Table 3).

Table 1. Demographic characteristics of the study subjects.

\begin{tabular}{ll}
\hline Age of the baby $(\mathrm{d})$ & $6.38 \pm 5.343$ \\
\hline Gestational age $(w)$ & $32.81 \pm 1.365$ \\
\hline Birth Weight of the baby & $1.67 \pm 0.184$ \\
\hline Gender & $12(57 \%)$ \\
\hline Male & $9(43 \%)$ \\
\hline Female & \\
\hline
\end{tabular}

Table 2. Comparison of mean total duration of sleep time per sleep period with nesting and routine care $(N=21)$.

\begin{tabular}{lll}
\hline & Mean $(\min )$ & $\begin{array}{l}\text { Standard } \\
\text { deviation }\end{array}$ \\
\hline Total duration of sleep time with nesting & 113 & 28 \\
\hline $\begin{array}{l}\text { Total duration of sleep time with routine } \\
\text { care }\end{array}$ & 86 & 27 \\
\hline
\end{tabular}

Duration of sleep time in each stages showed, duration of active sleep is significantly reduced (34.76) with nesting as compared to routine care (39.55) although which is not significant $(\mathrm{t}=1.134, \mathrm{P}=0.270)$ there is significant increase in quiet sleep $(63.62 \pm 17.957)$ with nesting than with routine care $(38.76 \pm 19.450)$ and indeterminate sleep time was increased (15.52 \pm 8.370$)$ with nesting as compared with sleep in routine 
care $(10.15 \pm 6.680)$ which is highly significant $(\mathrm{t}=4.570$, $\mathrm{p}<0.001),(\mathrm{t}=2.297, \mathrm{p}=0.003)$ at 0.05 level of significance (Tables 4-6).

Table 3. Effect of nesting on total duration of sleep time.

\begin{tabular}{|c|c|c|c|c|c|}
\hline Duration of sleep & Mean difference & $\begin{array}{l}\text { Standard } \\
\text { deviation }\end{array}$ & Paired $\mathbf{t}$ & df & Sig (2-tailed) $p$ \\
\hline Duration of sleep time with nesting vs. routine care & 26.119 & 24.278 & 4.93 & 20 & $p=0.001$ \\
\hline
\end{tabular}

Table 4. Effect of nesting on duration of sleep time in active sleep.

\begin{tabular}{|c|c|c|c|c|c|c|c|}
\hline & Mean & Std deviation & Mean difference & STD deviation & $\mathbf{t}$ & df & Sig (2-tailed) \\
\hline Duration of active sleep with nesting & 34.76 & 16.269 & -4.86 & 19.343 & -1.134 & 20 & 0.27 \\
\hline $\begin{array}{l}\text { Duration of active sleep with usual } \\
\text { procedure of swaddling }\end{array}$ & 39.55 & 14.78 & & & & & \\
\hline
\end{tabular}

Table 5. Effect of nesting on duration of quiet sleep time.

\begin{tabular}{|c|c|c|c|c|c|c|c|}
\hline & Mean & Std deviation & Mean difference & STD deviation & $\mathbf{t}$ & df & Sig (2-tailed) \\
\hline Duration of active sleep with nesting & 63.62 & 17.957 & 24.857 & 19.343 & 24.924 & 4.57 & 0 \\
\hline $\begin{array}{l}\text { Duration of active sleep with usual } \\
\text { procedure of swaddling }\end{array}$ & 39.55 & 19.45 & & & & & \\
\hline
\end{tabular}

Table 6. Effect of nesting on duration of sleep time in indeterminate sleep.

\begin{tabular}{|c|c|c|c|c|c|c|c|}
\hline & Mean & Std deviation & Mean difference & STD deviation & $\mathbf{t}$ & df & Sig (2-tailed) \\
\hline Duration of active sleep with nesting & 15.52 & 8.37 & 5.381 & 10.735 & 2.297 & 20 & 0.033 \\
\hline $\begin{array}{l}\text { Duration of active sleep with usual } \\
\text { procedure of swaddling }\end{array}$ & 10.14 & 6.68 & & & & & \\
\hline
\end{tabular}

\section{Discussion}

In neonatal intensive care unit preterm infants sleep get disturbed due to the effect of many factors like noise, light and lack of confined environment. This may be compensated by caring infant with nesting. In the present study it was observed that the total duration of sleep time was significantly higher (113 min) among infant with nesting as compared to routine care $(86 \mathrm{~min})$. But, duration of sleep time in each stage showed a statistical difference, wherein duration of active sleep was reduced with nesting when compared to routine care but it was not significant. There was significant increase in quiet sleep and indeterminate sleep time with nesting as compared with sleep in routine care. Our study findings are in accordance with the study conducted by Kihara and Nakamura, the study proved that infants experienced longer deep sleep hours those who were in a swaddled nesting support when compared to those without support [6]. The interventions used in our study were similar to the above mentioned study and the observations were also similar both before and after intervention. The present study also showed similar results irrespective of the groups evaluated for the sleep patterns in terms of sleep-wake cycles. Many studies have being done with various methods to improvise the sleep duration in infants one such is by using kangaroo care method by Begum et al. which showed a higher duration of sleep after the intervention than before intervention. The present study used different intervention method but both the studies had followed similar developmental care procedures and the neonatal examinations and observations at different sleep stages were same before, during and after intervention [7]. Nurse should engage in preventive and promote services for enhancing health. The study finding helps a neonatal nurse to recognize the importance of identifying sleep impairment of infants. Neonatal intensive care nurse should impart a concept regarding sleep pattern of infants to the new mother and her support person during admission to postnatal ward for better adaptation to the disease phase.

\section{Limitations}

The study was conducted among preterm infants between $30 \mathrm{w}$ to $36 \mathrm{w}$ of gestation. Sleep assessment tool is a reliable tool, which can be used by nurses to assess sleep of preterm infants. The small sample size and short duration of intervention also other limitations of the study. 


\section{Conclusion}

The findings of the research study showed that nesting is beneficial in improving sleep of preterm infants admitted in neonatal intensive care units. This study findings can be utilized for caring preterm infants in neonatal intensive care units and in situation where there is lack in parental care to prevent the crippling complications like abnormal psychomotor and neurological sequelae due to impaired sleep. Further studies are recommended in this regard to recommend nesting.

\section{Acknowledgement}

We warmly thank all of the study participants and their parents and members of NICU for their cooperation in connection with this study.

\section{Funding}

Self-funded

\section{Declaration of Conflicting Interest}

The authors have no conflicts of interest

\section{References}

1. Anders TF, Sadeh A, Appareddy V. Normal sleep in neonates and children. In: Ferber R, Kryger M. Principles and practice of sleep medicine in the child (3rd edn.). Philadelphia PA: WB Saunders 1995.

2. Astill Van der Heijden KB, Van I,Van S. Sleep, cognition and behavioral problems in school age children: acentury of research meta-analysed. Psychol Bull 2012; 138: 1109.
3. Hideki K, Tomohiko N. Nested and swaddled positioning support in the prone position facilitates sleep and heart rate stability in very low birth weight infants. Res Rep Neonatol 2014; 3: 11-14.

4. Ingersoll EW, Thoman EB. Sleep/wake states of preterm infants: stability, developmental change, diurnal variation, and relation with caregiving activity. J Child Develop 1999; 70: $1-10$

5. Sheldon SH. Sleep in infants and children. Sleep Med Philadelphia PA: Hanley and Belfus Inc. 2002.

6. Kihara H, Nakamura T. Nested and swaddled positioning support in the prone position facilitates sleep and heart rate stability in very low birth weight infants. Res Rep Neonatol 2013; 3: 11-14.

7. Begum EA, Bonno M, Ohtani N, Yamashita S, Tanaka S, Yamamoto $H$. Cerebral oxygenation responses during kangaroo care in low birth weight infants. BMC Pediatr 2008; 8: 51.

\section{*Correspondence to}

\section{Mony K}

Department of Pediatric Nursing

MOSC College of Nursing

Malankara Orthodox Syrian Church Medical College

India 